\title{
Stabilization of Molecular Structure Membranes of Preserved RBCs by Means Nanotechnology
}

\author{
Andrey $\mathbf{B}^{1,2,3 *}$, Elena $\mathbf{M}^{2,3}$, Vadim $\mathbf{Y}^{2,3}$ and Ekateryna $\mathrm{B}^{1}$ \\ ${ }^{1}$ Laboratory of Applied Nanotechnology of Belousov, Ukraine \\ ${ }^{2}$ Kharkov Medical Academy of Postgraduate Education, Ukraine \\ ${ }^{3}$ Kharkov Regional Center of Blood Service, Ukraine
}

*Corresponding author: Andrey Belousov, Head Laboratory of Applied

Nanotechnology of Belousov, Pr Nauky, 31-v, fl. 32, Kharkov, 61072, Ukraine, Tel: 38050-915-18-89; Email: an.belousov2012@yandex.ua

\section{Abstract}

This study was devoted to the learning changes in the structure of erythrocyte membranes at the level of molecular bonds during their storage at a positive temperature by means method of infrared spectroscopy (IR). Objects of research were red blood cells (RBCs) into bags containing preservative CPD and RBCs into bags containing preservative CPDA-1. As membrane protective used saline which had previously been treated with magnetite nanoparticles (ICNB) by the Belousov's method. The physiological solution that was treated with nanoparticles was added to the preserved RBCs according to the developed method. Sample of control was the addition of intact saline. Analysis of changes occurring in the IR spectra of samples of control and test in the CPD medium was showed that during the first 28 days storage of: 1 . In the suspension of control of the RBCs, noticeable destructive changes in the molecular structure membrane of erythrocytes at the 14th day storage begins. After three weeks, the molecular structure membrane of erythrocytes is completely destroyed; 2 . In the sample of test there was a weakening and rupture of molecular bonds only at the 28th day storage of RBCs. Complete destruction of the structure of membrane of erythrocytes occurs at the 35th day storage. Analysis of changes occurring in the IR spectra of samples of control and test in the CPDA-1 medium was showed that during 49 days storage of: 1 . In the suspension of control of RBCs noticeable destructive changes in the molecular structure begins in four weeks, and after six weeks storage the molecular structure of erythrocytes membrane are completely destroyed; 2 . In the sample of test, a significant weakening of intra-and intermolecular bonds in the structure of erythrocytes membrane occurs after six weeks. However, the complete destruction of the structure is not observed. After seven weeks storage of erythrocytes obvious violations of the molecular structure of lipids and proteins that make up the RBCs are visible but some of the strongest compounds still remain.

In general, the results clearly showed that the presented method of application of nanotechnology significantly increases the storage time of RBCs in different versions of preservatives due to mechanisms to reduce violations of the molecular structure of proteins and lipids in the erythrocyte membranes. Presented method of application of nanotechnology is not 


\section{Medical Journal of Clinical Trials \& Case Studies}

only safe for use in practice in the Blood Service, Transfusiology and Hematology, but also is the most promising innovation project.

Keywords: Nanotechnology; Preserved Red Blood Cells (RBCs); Magnetite Nanoparticles (ICNB); Method of Infrared Spectroscopy (IR); Molecular Structure; Storage Time of RBCs

\section{Actuality}

For several decades RBCs components have been prepared as concentrates suspended in nutrient additive solution, which preserves and extends the shelf-life of the RBCs component, allowing up to 6-7 weeks of refrigerated storage [1]. Nevertheless, during storage RBCs undergo a complex and progressive accumulation of physicochemical changes, collectively referred to as the RBCs storage lesion [2,3]. Recent clinical studies have identified RBCs transfusion as an independent risk factor for increased morbidities and mortalities in certain groups of patients, including trauma, cardiac surgery and the critically-ill [4-6]. Additionally, some of these studies have identified that older stored RBCs are more strongly implicated in poorer outcomes compared to fresher RBCs [6]. In order to address these concerns, there is renewed interest to better understand the RBCs storage lesion and to find ways to ameliorate the deleterious effects of storage, thereby improving the quality, efficacy and safety of RBCs components for all transfusion recipients.

While increased research effort is being directed to better understand the effects of storage on RBCs and the potential impact on transfusion outcomes, slower progress is being made in finding ways to deter the detrimental effects of the RBCs storage lesion [7].

Despite the RBCs having been a favorite experimental model for cellular biologists and biochemists, RBCs storage research has repeatedly demonstrated that a lot of fundamental biology about RBCs is still not well understood. The complexity of the inter-relationship between RBCs biochemistry, cytoskeletal structure and membrane properties have made it difficult to predict how RBCs will respond to different storage conditions. Exposure of RBCs to non-physiological storage environments has pointed to the existence of previously unknown biochemical mechanisms in RBCs, including apoptotic-like processes, ion and osmotic channels that behave differently than expected, exposure of new or altered receptors possibly due to oxidative and/or protease/glycosidase activities or altered senescence [8$11]$.
The benefits gained by improved RBCs component quality should more than justify any real or perceived inconvenience to the blood services in implementing adjustments to their processing procedures or additional processing costs of the introduction of new generation RBCs additive solutions.

Currently, nanotechnology opens up new prospects for the study of not only the mechanisms of cell damage, but also the development of effective and safe methods of cells storage outside the body.

In Ukraine, the first standardized and biocompatible magnetite nanoparticles for medical use were manufactured and patented in 1998. These are intracorporeal nanobiocorrector of brand ICNB, magnetcontrolled sorbent of brand MCS-B, and biologically active nanodevice of brand Micromage-B [12].

It is well established that the magnetite nanoparticles effectively modulate the metabolic processes in leukocytes, regulate activity of the enzyme link of the antioxidant system in erythrocytes in healthy and sick patients [13-15]. Previously the complex investigations that were performed in the study of the influence on metabolism of cells by preparations of nanotechnology show that in whole standardized biocompatibility of magnetite nanoparticles have nonspecific and modulated effect on metabolic processes. Research of ultrastructure investigations of the reticuloendothelial system (liver, lungs and kidneys) it was proved that after injection of biocompatibility magnetite nanoparticles into a vein caused nonspecific activation of the metabolic processes, increase adaptive mechanisms and potential of organelle cells, acceleration of reparative processes a level of membranes and macromolecules [14,16,17]. Existing sorption and indirect (magnetic) effects not only allow selectively absorb the protein of surface membrane cells by magnetite nanoparticles (according to the principle of magnetospheres), but also to prevent the oxidative modification of proteins by way of stabilizing the active groups, normalizing a state of receptors that are located on the surface membrane of cells, increasing activity of enzymes' membrane-bound [18-20]. 


\section{Medical Journal of Clinical Trials \& Case Studies}

Recent scientific work related to use of magnetite nanoparticles (ICNB) in contrast means in an MRI investigation of cancer reliably was shown that nanoparticles cause reversible changes associated with a temporary increase in the mobility of hydrogen protons in the pericellular fluid that inevitably modifies the metabolism in malignant cells [21]. The results of these investigations have not only widened the understanding of the mechanisms of action of nanoparticles on condition outside and intracellular spaces but also have revealed new aspects of the cellular(cells) metabolism, determined the membrane role of cellular enzymes in the regulation processes of metabolism [19,22-24].

Also, it was established that extracorporeally processing the blood by nanoparticles of MCS-B reliably reduces activity of $\mathrm{Ca}, \mathrm{Mg}$ - ATPHese of erythrocytes.

Currently, studies have shown that magnetite nanoparticles are able to inhibit hemolysis of heparinized blood, increase the activity of ATP and 2.3 DPH in red blood cells, regulate transmembrane metabolism and inhibit eryptosis [19,25,26].

In our recent studies, it has been found that physiologic solution $\mathrm{NaCl}$ which previously was processed by magnetite of nanoparticles (ICNB) and added to the preserved of the red blood cells actively inhibits of hemolysis processes of RBCs at the storage stages at a positive temperature (Figure 1). A comprehensive analysis of data revealed the primary mechanisms of the effect modernized of the saline solution on the preserved RBCs. It was established that saline $\mathrm{NaCl}$, which had previously been processed by magnetite nanoparticles (ICNB) had a marked membrane-stabilizing effect, inhibits hemolysis and increasing the sedimentation stability of preserved RBCs. In General, these effects provide the sustainability of the functional activity of preserved RBCs in during storage. The optimization results were obtained in creating a simple and practical method of additive modernization of preservation solutions that does not violate the compliance requirements, improves the quality, efficiency and safety transfusion of RBCs [27-29].

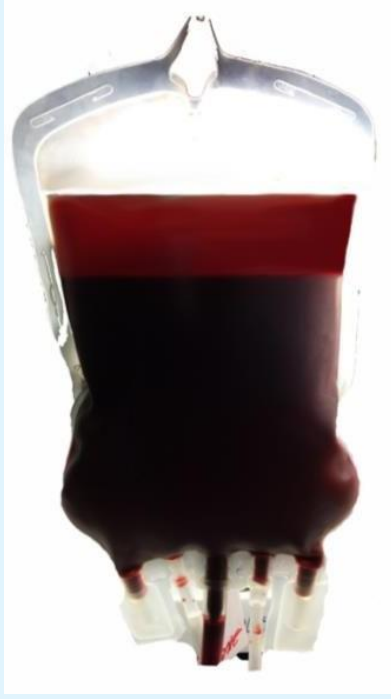

Control

(Free $\mathrm{Hb}, \mathrm{g} / \mathrm{l}=7.8 \pm 0.1$; Calculation HCT, $\%=1.84 \pm 0.1$ )

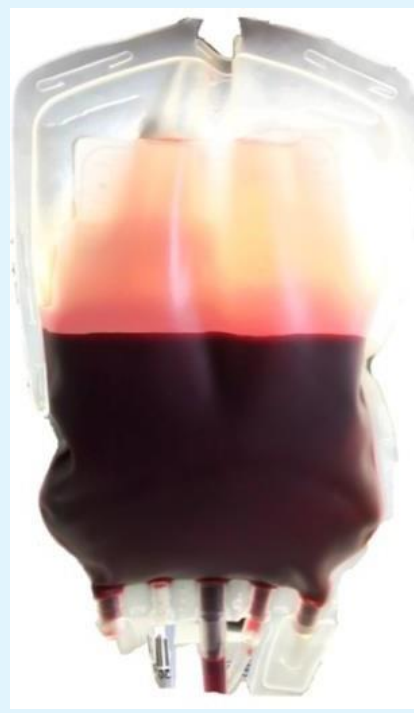

Test

(Free $\mathrm{Hb}, \mathrm{g} / \mathrm{l}=1.7 \pm 0.1$;

Calculation HCT, $\%=0.4 \pm 0.1$ )

Figure 1: The hemolysis inhibition effect with using method of additive modernization of preservative solutions adapted to the manufacture process on the 35 th day of the study. 


\section{Medical Journal of Clinical Trials \& Case Studies}

However, comprehensive analysis of the above data revealed only the primary mechanisms of the effect modernized of the saline solution on the preserved RBCs. Taking this into account, it was decided to conduct an indepth study of changes in the structure of erythrocyte membranes at the level of molecular bonds during their storage. One of the effective methods of these studies is the method of infrared spectroscopy (IR) [30].

Infrared spectroscopy (IR) is a method of identifying and analyzing chemical compounds. An infrared beam is directed at a sample, and by measuring the radiation that is absorbed by the sample at different frequencies, one can tell what types of molecules make up the sample [31,32]. The method is based on the phenomenon of absorption of electromagnetic radiation in the infrared range by groups of atoms of the object under study. When the molecule is irradiated with infrared radiation, quanta are absorbed, the frequencies of which correspond to the frequencies of valence, deformation and libration vibrations of molecules. IR allows us to trace the changes in all the main types of bonds in the molecules of the substances under study [33-36]. The spectrum is displayed with a graph that shows at which frequency and how much absorption occurred. Because different molecules absorb the radiation at specific frequencies in known amounts, the spectrum can be used to identify the sample at a molecular level. Infrared spectroscopy is used in research to identify samples, do quantitative analysis, or detect impurities. Infrared spectroscopy can be used on gaseous, liquid, or solid samples and does not destroy the sample in the process. IR is widely used for the analysis of biological fluids, in particular blood and its fragments [37].

Thus, the next purpose of research was the study of changes in the molecular structure of erythrocyte membranes in additive modernization of preservation solutions of RBCs at the storage stages at a positive temperature.

\section{Materials and Methods}

\section{Materials}

1. Standardized intracorporeal nanobiocorrector of ICNB was taken as magnetite nanoparticles. Magnetite nanoparticles synthesized by co-precipitation method. The main physics and chemical properties of ICNB the following data and also in Tables 1-4; Figures 2 \& 3 were presented:

- Concentration of the colloidal solution of magnetite nanoparticles in physiology solution of $\mathrm{NaCl}$ is $0.0225 \%$.

- Theoretical osmolality of colloid solution is 500 mosmol/l

- Size of magnetite nanoparticles is 6-12 nm;

- Total area of surface magnetite of nanoparticles Ss = $800-1200 \mathrm{~m}^{2} / \mathrm{g}$

- Magnetization of saturation Is $=2.15 \mathrm{KA} / \mathrm{m}$;

- $\zeta$ - potential $=-19 \mathrm{mV}$.

2. $0.9 \% \mathrm{NaCl}$ solution.

3. $0.9 \% \mathrm{NaCl}$ solution which previously was processed by ICNB in ratio 4:1.

\begin{tabular}{|c|c|c|c|c|c|c|}
\hline Phase name & a $(\AA)$ & b $(\AA))$ & c $(\AA \AA)$ & alpha (degree) & beta (degree) & amma (degree \\
\hline magnetite low & 8.387836 & 8.387836 & 8.387836 & 90.00 & 90.00 & 90.00 \\
\hline magnetite low, syn & 5.930687 & 5.930687 & 14.705912 & 90.00 & 90.00 & 120.00 \\
\hline Johannsenite & 9.891680 & 9.059276 & 5.282908 & 90.00 & 105.54 & 90.00 \\
\hline
\end{tabular}

Table 1: The calculated lattice parameters of the phases.

\begin{tabular}{|c|c|c|c|c|c|c|c|c|}
\hline Compound & Weight\% & Std Err & El & Weight\%/ $\mathbf{O}_{2}$ & Std Err & El & Weight\% & Std Err \\
\hline $\mathrm{Fe}_{3} \mathrm{O}_{4}$ & 97.37 & 0.09 & $\mathrm{Fe}$ & 68.4 & 0.07 & $\mathrm{Fe}$ & 97.62 & 0.09 \\
\hline $\mathrm{CaO}$ & 2.26 & 0.07 & $\mathrm{Ca}$ & 1.71 & 0.05 & $\mathrm{Ca}$ & 2.3 & 0.07 \\
\hline $\mathrm{P}_{2} \mathrm{O}_{5}$ & 0.28 & 0.027 & $\mathrm{Px}$ & 0.122 & 0.012 & $\mathrm{Px}$ & 0.157 & 0.015 \\
\hline $\mathrm{MnO}$ & 0.255 & 0.013 & $\mathrm{Mn}$ & 0.198 & 0.01 & $\mathrm{Mn}$ & 0.278 & 0.014 \\
\hline $\mathrm{SiO}_{2}$ & 0.098 & 0.027 & $\mathrm{Si}$ & 0.046 & 0.013 & $\mathrm{Si}$ & 0.059 & 0.016 \\
\hline $\mathrm{SO}_{3}$ & 0.032 & 0.013 & $\mathrm{Sx}$ & 0.0126 & 0.0051 & $\mathrm{Sx}$ & 0.0164 & 0.0066 \\
\hline $\mathrm{Cl}$ & 0.028 & 0.009 & $\mathrm{Cl}$ & 0.028 & 0.009 & $\mathrm{Cl}$ & 0.038 & 0.012 \\
\hline
\end{tabular}

Table 2: Determination of percent composition of the ICNB by X-ray spectrometer ARL OPTIM'X (semi- quantitative analysis). 


\section{Medical Journal of Clinical Trials \& Case Studies}

\begin{tabular}{|c|c|c|c|}
\hline Phase & Formula & Space group & № Card Database ICDD \\
\hline magnetite low & $\mathrm{Fe} 2.886 \mathrm{O}_{4}$ & $227: \mathrm{Fd}-3 \mathrm{~m}$, choice-2 & 10861339 (ICDD) \\
\hline magnetite low, syn & $\mathrm{Fe}_{3} \mathrm{O}_{4}$ & $166: \mathrm{R}-3 \mathrm{~m}$, hexagonal & 10716766 (ICDD) \\
\hline Johannsenite & $\mathrm{Ca} \mathrm{Mn}+2 \mathrm{Si}_{2} \mathrm{O}_{6}$ & $15: \mathrm{C} 12 / \mathrm{c} 1$, unique-b,cell-1 & 380413 (ICDD) \\
\hline
\end{tabular}

Table 3: X-ray analysis of ICNB in X-ray diffractometer Rigaku Ultima IV ( $\mathrm{CuK} \alpha, \mathrm{K} \beta$ filter - Ni), one-coordinate DTeX semiconductor detector.

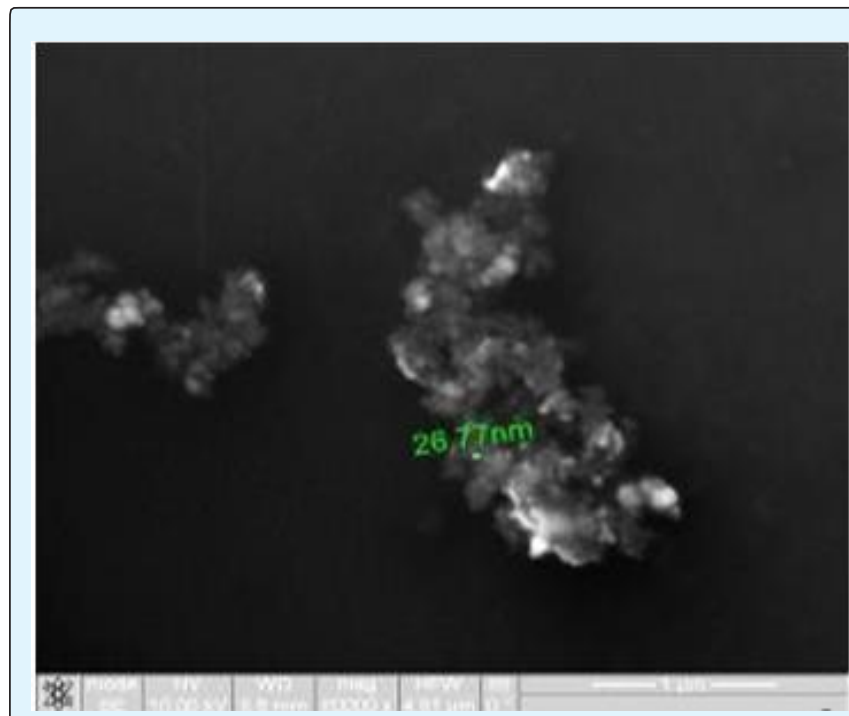

Figure 2: Study of magnetite nanoparticles with use microscope ion-electronic raster-type Quanta 2003 D.

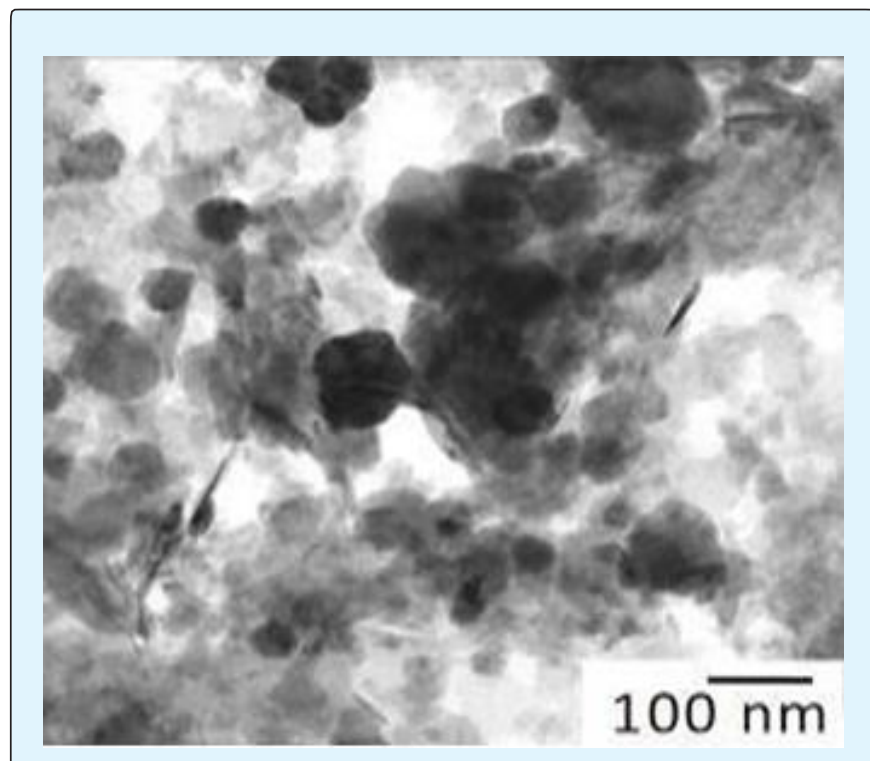

Figure 3: Study of magnetite nanoparticles with use microscope electronic translucent JEM-2100.

\begin{tabular}{|c|c|}
\hline $\begin{array}{c}\text { Phases (Method of corundum } \\
\text { numbers) }\end{array}$ & Content, $\%$ \\
\hline magnetite low & 71 \\
\hline magnetite low, syn (hexagonal) & 29 \\
\hline
\end{tabular}

Table 4: The phases of magnetite of nanoparticles (RIR method; error $8 \pm 3 \%$ ).

\section{Objects of Research}

- Red blood cells (RBCs) into bags containing anticoagulant citrate, nutrient phosphate and dextrose (CPD);

- Red blood cells (RBCs) into bags containing anticoagulant citrate, nutrient phosphate, dextrose and adenine (CPDA-1).

Of each bag of $3 \mathrm{ml}$ amounts of red blood cells was distributed into 20 sterile glass tubes. Then, into the first 10 tubes of control were added of $2 \mathrm{ml}$ amounts $0.9 \%$ $\mathrm{NaCl}$ solution. Into the next 10 tubes of test were added of $2 \mathrm{ml}$ amounts $0.9 \% \mathrm{NaCl}$ solution, which previously was processed by ICNB.

Thus, the distribution of tubes was as the follows:

Tubes of control:

- $3 \mathrm{ml}$ of red blood cells (CPD) $+2 \mathrm{ml} 0.9 \% \mathrm{NaCl}$ solution $(\mathrm{n}=10)$;

- $3 \mathrm{ml}$ of red blood cells (CPDA-1) $+2 \mathrm{ml} 0.9 \% \mathrm{NaCl}$ solution $(\mathrm{n}=10)$.

Tubes of test:

- $3 \mathrm{ml}$ of red blood cells (CPD) $+2 \mathrm{ml} 0.9 \% \mathrm{NaCl}$ solution that previously was processed by ICNB in ratio $4: 1$ $(\mathrm{n}=10)$;

- $3 \mathrm{ml}$ of red blood cells (CPDA- 1 ) $+2 \mathrm{ml} 0.9 \% \mathrm{NaCl}$ solution that previously was processed by ICNB in ratio $4: 1(n=10)$.

IR Spectrophotometer-29 (LOMO), working in NSC Kharkov Institute of Physics and Technology of the National Academy of Sciences of Ukraine, was used for registration of absorption spectra of an aqueous solution of erythrocytes in the IR range. The spectra were recorded in the range of $4000-400 \mathrm{~cm}^{-1}$ (from 2 to 25 $\mathrm{mkm}$ - middle infrared region). 
Calibration was carried out on the spectrum of polystyrene with known frequencies of absorption maxima. The amendment amounted to an average of 10-5 $\mathrm{cm}^{-1}$.

Liquid water is characterized by strong absorption in the study range, so to record the spectra of aqueous solutions is necessary to obtain a thin layer of the substance. For this purpose, two thin plates of $\mathrm{CaF}_{2}$ material transparent in the mid-IR range that does not have its own characteristic absorption bands, which could affect the interpretation of the IR spectrum of the aquatic solution, were used. A drop of the test liquid was crushed between two round plates $\mathrm{CaF}_{2}$ and installed in the measuring channel of the device. The same plates were installed in the comparison channel, but without liquid. Spectral recording was carried out immediately after placing the sample in the device and lasted 10 minutes. The temperature in the chamber was $25-30^{\circ} \mathrm{C}$.
Tests were carried out in eight stages: day 1 - I, day 7 II, day 14 - III, day 21 - IV, day 28 - V, day 35 - VI, day 42 VII, day 49 - VIII.

The blood after performance of the biochemical investigation was stored in the refrigerating chamber at temperature $+4^{\circ} \mathrm{O}$.

Statistically processing the obtained results was carried out by parametrical method of variation statistics by Student criterion. Processing the obtained data was carried out by means of Excel.

\section{Results and Discussion}

IR absorption spectra at the initial stage of the study of RBCs suspensions in the control and test in ranges 400 $1300 \mathrm{~cm}^{-1}$ and $1200-4000 \mathrm{~cm}^{-1}$ are shown in Figures $4 \& 5$.

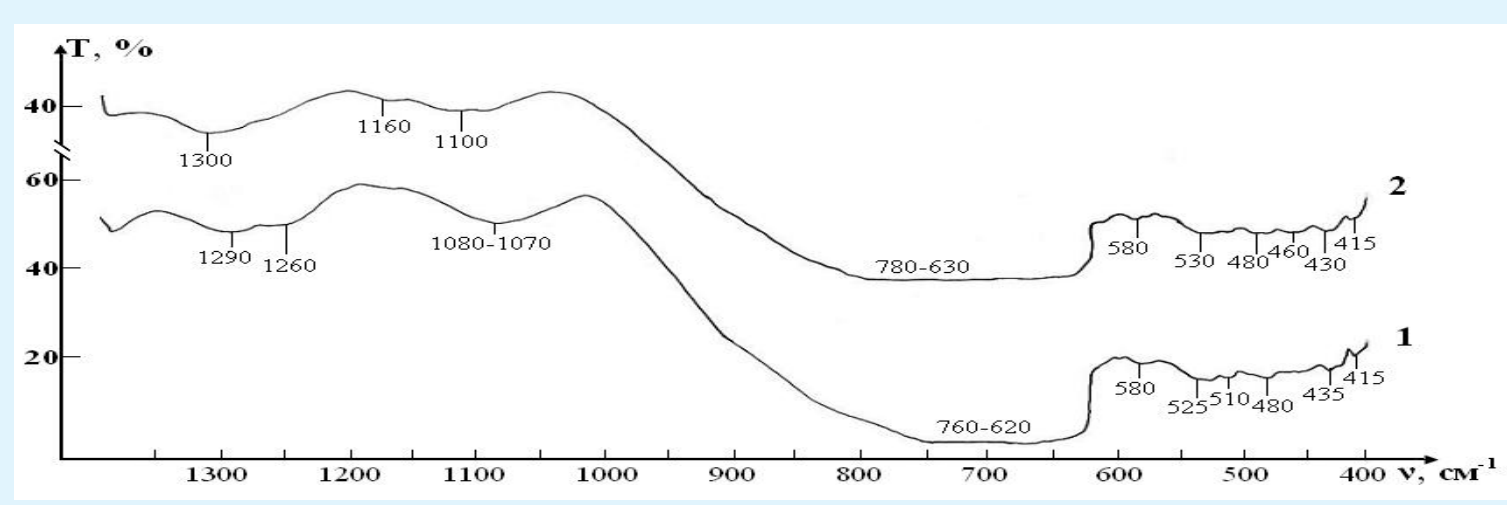

Figure 4: IR absorption spectra of initial erythrocyte suspensions in the range 400-1300 $\mathrm{cm}^{-1}$ : curve 1-control; curve 2 - test.

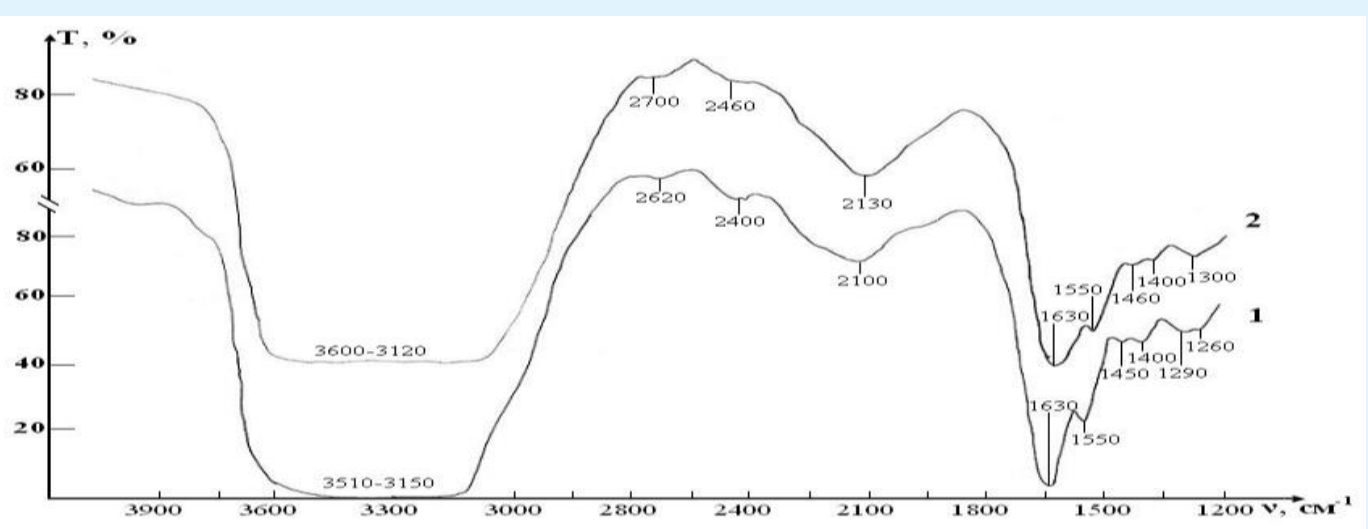

Figure 5: IR absorption spectra of initial erythrocyte suspensions in the range 1200-4000 $\mathrm{cm}^{-1}$ : curve 1- control; curve 2 - test. 


\section{Medical Journal of Clinical Trials \& Case Studies}

Since the basis of the studied suspensions of RBCs is liquid water, the most intense and broad bands of the spectrum correspond to different types of vibrations of molecules $\mathrm{H}_{2} \mathrm{O}$ :

1. The strong absorption in the range of $800-600 \mathrm{~cm}^{-1}$ corresponds to the librational modes of $\mathrm{H}_{2} \mathrm{O}$ (Figure 4).

2. Deformation vibrations of $\mathrm{N}-\mathrm{O}-\mathrm{N}$, due to changes in the angles of valence bonds, look like a narrow intense band $1630 \mathrm{~cm}^{-1}$ (Figure 5).

3. Composite vibration mode of deformation and libration vibrations of $\mathrm{H}_{2} \mathrm{O}$ molecules lies in the range of 2150 $2100 \mathrm{~cm}^{-1}$ (Figure 5).
4. The main band of valence vibrations caused by changes in the bond lengths in the water molecule covers the spectral range of $3600-3000 \mathrm{~cm}^{-1}$ (Figure 5).

In addition, the spectrum has a number of bands corresponding to the preservative for RBCs, which is contained in saline:

- Series of small range peaks: 415, 435, 480, 510, 530 and $580 \mathrm{~cm}^{-1}$ (Figure 4).

- Wide band with highs in the area of $1100 \mathrm{~cm}^{-1}$ (Figure 4).

\begin{tabular}{|c|c|c|}
\hline \multicolumn{2}{|c|}{$\begin{array}{c}\text { IR absorption spectra of initial erythrocyte suspensions } \\
\text { in different ranges }\left(\mathrm{cm}^{-1}\right)\end{array}$} & Characteristic of bands \\
\hline Control & Test & \\
\hline 415 & 415 & \\
\hline \multicolumn{2}{|l|}{435} & \\
\hline & 450 & \\
\hline 480 & 480 & \multirow{5}{*}{$\begin{array}{l}\text { Vibrational modes of chemical compounds that constitute } \\
\text { the preservative for RBCs }\end{array}$} \\
\hline 510 & 510 & \\
\hline & 520 & \\
\hline \multicolumn{2}{|l|}{525} & \\
\hline 580 & 580 & \\
\hline $760-620$ & $780-630$ & Librational mods of $\mathrm{H}_{2} \mathrm{O}$ \\
\hline $1080-1070$ & 1100 & \\
\hline & 1160 & \multirow{2}{*}{ Bands of preservative } \\
\hline 1260 & & \\
\hline \multirow[t]{2}{*}{1290} & & \multirow{5}{*}{\begin{tabular}{|c|} 
Fluctuations in the ring structure of the protein and Amide \\
III \\
Bands of preservative \\
$\begin{array}{c}\text { Deformation vibrations of the } \mathrm{d}\left(\mathrm{CH}_{3}\right) \text { in the structure of } \\
\text { lipids and proteins }\end{array}$
\end{tabular}} \\
\hline & 1300 & \\
\hline 1400 & 1400 & \\
\hline \multirow[t]{2}{*}{1450} & & \\
\hline & 1460 & \\
\hline 1550 & 1550 & Valence vibrations of $n(\mathrm{~N}-\mathrm{H})+\mathrm{n}(\mathrm{C}-\mathrm{N})$ of Amide II \\
\hline 1630 & 1630 & Deformation vibrations of $\mathrm{H}-\mathrm{O}-\mathrm{H}$ \\
\hline \multirow[t]{2}{*}{2100} & & \multirow{2}{*}{$\begin{array}{c}\text { Composite vibration mode of deformation and libration } \\
\text { vibrations of } \mathrm{H}_{2} \mathrm{O} \text { molecules }\end{array}$} \\
\hline & 2130 & \\
\hline \multicolumn{2}{|l|}{2400} & \multirow{4}{*}{ Bands of saline } \\
\hline & 2460 & \\
\hline \multicolumn{2}{|l|}{2620} & \\
\hline & 2700 & \\
\hline $3510-3150$ & $3600-3120$ & Band of valence vibrations of $\mathrm{H}-\mathrm{O}-\mathrm{H}$ \\
\hline
\end{tabular}

Table 5: Identification of absorption bands in the IR spectra of the initial RBCs suspension.

-Weak intensity peaks in the region of 1260 and $1400 \mathrm{~cm}^{-1}$ (Figure 3).

Thus, three characteristic peaks can be distinguished in the spectrum, which are directly related to intramolecular fluctuations in the structure of erythrocytes: 1290, 1450 and $1550 \mathrm{~cm}^{-1}$ (Figure 3). Identification of absorption bands in the IR spectra of the initial RBCs suspension is presented in the Table 5. The spectral range in which the characteristic bands corresponding to the main fragments of the structure of RBCs are presented in Figure 4 and Figure 5. These bands can be identified as follows: Experiment 1 (preservative CPD). A sample of control of the RBCs suspension in preservative CPD with intact saline solution on five stages 
of the study is presented in the Fig. 4. The peak of weak intensity of $1290 \mathrm{~cm}^{-1}$ can be attributed to fluctuations in the ring structure of the protein, as well as Amide III [37]. The weak peak of $1450 \mathrm{~cm}^{-1}$ refers to the deformation vibrations $\delta\left(\mathrm{CH}_{3}\right)$ in the structure of lipids and proteins [38,39]. Sharp band of average intensity at $1550 \mathrm{~cm}^{-1}$ caused by valence vibrations of $v(\mathrm{~N}-\mathrm{H})+v(\mathrm{C}-\mathrm{N})$ Amide II [37]. Fig. 3 shows that after a week (stage II) of sample exposure the intensity of all these peaks associated with $\mathrm{C}-\mathrm{N}$ valence vibrations and $\mathrm{N}-\mathrm{H}$ deformation vibrations $\left(1290,1450\right.$ and $\left.1550 \mathrm{~cm}^{-1}\right)$ is decreases. This may indicate the beginning of changes in the secondary structure of the protein. After two weeks (stage III), the band $1290 \mathrm{~cm}^{-1}$ is shifted towards high frequencies $\left(\rightarrow 1300 \mathrm{~cm}^{-1}\right)$ and turns into a small bend, the band 1450 $\mathrm{cm}^{-1}$ becomes barely noticeable shoulder, and the most intense peak of Amide II in the region of $1550 \mathrm{~cm}^{-1}$ is significantly weakened.

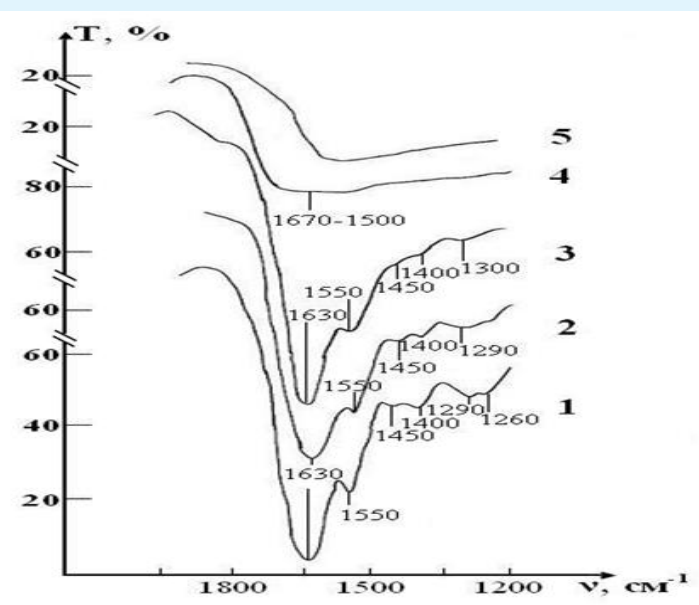

Figure 4: IR absorption spectra of the sample of control consisting of RBCs suspension in native saline solution in CPD medium: curve 1- stage I (day 1); curve 2- stage II (day 7); curve 3 - stage III (day 14); curve 4 - stage IV (day 21); curve 5 - stage V (day 28).

These changes indicate the degradation of the molecular structure of the substance and the weakening of intra - and intermolecular bonds. After three weeks of storage (stage IV) in the control IR spectrum completely smoothed, disappear all the bands of red blood cells, there is a wide band of blurred vibrations in the range of $0-\mathrm{H}$ $\left(1650-1500 \mathrm{~cm}^{-1}\right)$. After four weeks of storage (stage V) changes in the spectrum are not observed. Given the latter, studies of IR absorption spectra were impractical in the next planned stages (stages VI, VII).
A sample of test of the RBCs suspension in preservative $\mathrm{CPD}$ with saline solution that previously was processed by ICNB is presented in the Figure 5 .

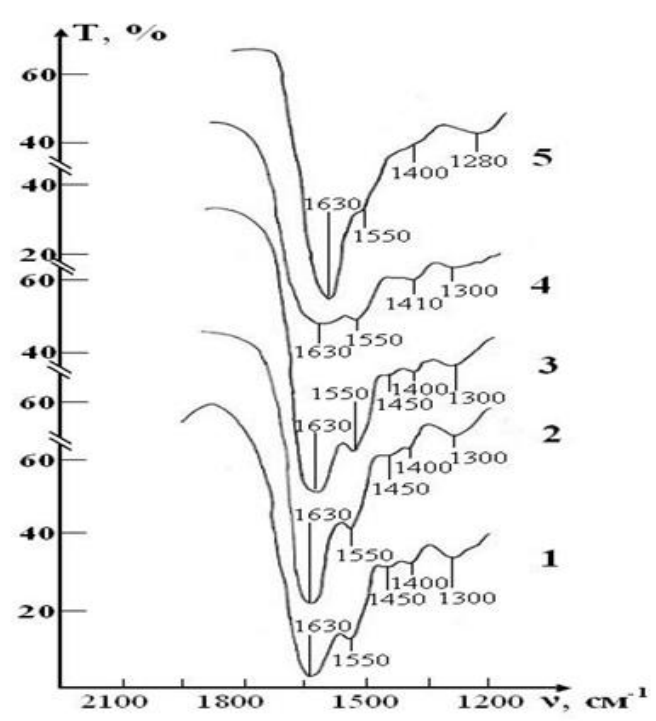

Figure 5: IR absorption spectra of a sample consisting of a suspension of erythrocytes in a saline solution treated with magnetite nanoparticles in CPD medium: curve 1- stage I (day 1); curve 2 - stage II (day 7); curve 3 - stage III (day 14); curve 4 - stage IV (day 21); curve 5- stage $\mathrm{V}$ (day 28).

The IR spectrum of erythrocyte suspension in the sample of test at the stage I is almost identical to the spectrum in the control, except that instead of the doublet $1290-1260 \mathrm{~cm}^{-1}$ there is a band $1300 \mathrm{~cm}^{-1}$ with a barely noticeable shoulder $1240 \mathrm{~cm}^{-1}$ (Figure 5). Over the next two weeks, no noticeable changes in the spectrum that would indicate disturbance of the molecular structure of RBCs were observed.

The intensity of the bands in zone 1300 and $1550 \mathrm{~cm}^{-1}$ are decreases, and the band $1450 \mathrm{~cm}^{-1}$ completely disappears on 21th day (stage IV) storage of RBCs. These changes indicate that the molecular structure of proteins and lipids of erythrocyte membranes begins to deteriorate. Hardly noticeable excesses associated with intramolecular vibrational against the background of water and bands preservative solution in the IR spectrum in during storage of RBCs appear only on the 28th day (stage V) of observation. Thus, the molecular structure of RBCs is not completely destroyed. 


\section{Summary of Experiment 1}

Analysis of changes occurring in the IR spectra of samples of control and test in the CPD medium was showed that during the first 28 days storage of:

1. In the suspension of control of the RBCs, noticeable destructive changes in the molecular structure membrane of erythrocytes at the 14th day (stage III) storage begins. After three weeks, the molecular structure membrane of erythrocytes is completely destroyed.

2. In the sample of test there was a weakening and rupture of molecular bonds only at the 28th day storage of RBCs. Complete destruction of the structure of membrane of erythrocytes occurs at the 35th day (stage VI) storage.

Experiment 2 (preservative CPDA-1).

A sample of control of the RBCs suspension in preservative CPDA-1 with intact saline solution on main stages of the study is presented in the Figure 6.

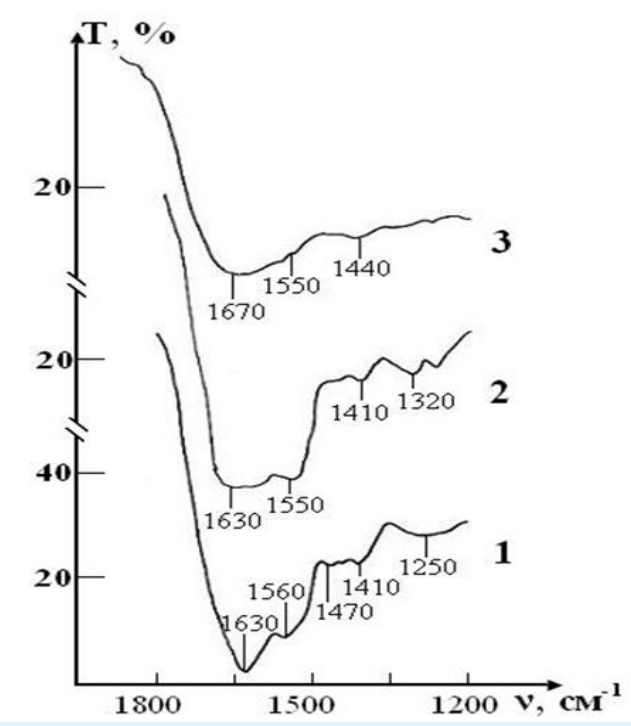

Figure 6: IR absorption spectra of the sample of control consisting of RBCs suspension in native saline solution in CPDA-1 medium on main stages of the study: curve 1- stage I (day 1); curve 2 - stage V (day 28); curve 3 - stage VII (day 42).

The IR spectrum of the initial sample contains the same bands of functional groups, which were described above in experiment 1 . However, there are some differences in their intensity due to the characteristics of the blood donor from which the sample was obtained.
After three-week storage of RBCs (stage IV) in the spectrum there were no noticeable changes that would indicate disturbance of the molecular structure of the erythrocyte membrane.

After four weeks (stage V), noticeable changes appear in the spectrum (some bands are smoothed, their intensity decreases, small peaks disappear). These changes indicate that the molecular structure of proteins and lipids of erythrocyte membranes begins to break down. After five weeks (stage VI) no significant changes in the spectrum were found. After six weeks of RBCs storage (stage VII) barely noticeable excesses associated with intramolecular oscillations are observed in the spectrum against the background of a wide blurred band in the vibration range $\mathrm{O}-\mathrm{H}\left(1650-1500 \mathrm{~cm}^{-1}\right) \mathrm{H}_{2} \mathrm{O}$ that indicates the complete destruction of the molecular structure of erythrocyte membrane.

A sample of test of the RBCs suspension in preservative CPDA-1 with saline solution that previously was processed by ICNB on main stages of the study is presented in the Figure 7.

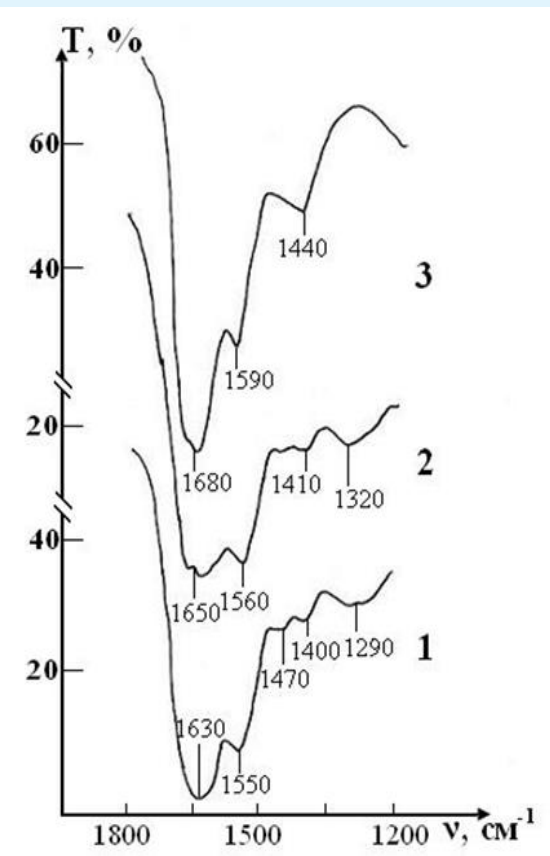

Figure 7: IR absorption spectra of the sample of test consisting of RBCs suspension in preservative CPDA-1 with saline solution that previously was processed by ICNB on main stages of the study: curve 1- stage I (day 1); curve 2 - stage V (day 28); curve 3 - stage VII (day 42). 


\section{Medical Journal of Clinical Trials \& Case Studies}

The dynamics of changes in the molecular structure of this sample is shown in Figure 7 demonstrates that it remains fully stable for four weeks storage of RBCs. The first signs of a slight decrease in the intensity of the lipid and protein of bands appear after four weeks storage of RBCs. Nevertheless these changes are much less pronounced than in the control sample of this series.

After six weeks, the spectrum changes mainly due to the shift of bands in the high-frequency region and smoothing of small peaks. This indicates a significant weakening of intra-and intermolecular bonds in the structure of RBCs. However, complete destruction of the membrane structure of RBCs is not observed.

After seven weeks of storage, only one weak band of erythrocytes remains in the spectrum, corresponding to the valence vibrations of the most stable bond $v(\mathrm{~N}$ $\mathrm{H})+v(\mathrm{C}-\mathrm{N})$ of Amide II, which previously (in sample of control) experienced a significant shift in the highfrequency region due to the weakening of this bond. The bands of deformation vibrations of protein and lipid molecules disappear, i.e. the molecular structure of erythrocytes is disturbed.

\section{Summary of Experiment 2}

Analysis of changes occurring in the IR spectra of samples of control and test in the CPDA-1 medium was showed that during 49 days storage of:

1. In the suspension of control of RBCs noticeable destructive changes in the molecular structure begins in four weeks, and after six weeks storage the molecular structure of erythrocytes membrane are completely destroyed.

2. In the sample of test, a significant weakening of intraand intermolecular bonds in the structure of erythrocytes membrane occurs after six weeks. However, the complete destruction of the structure is not observed. After seven weeks storage (stage VIII) of erythrocytes obvious violations of the molecular structure of lipids and proteins that make up the RBCs are visible but some of the strongest compounds still remain.

\section{Conclusion}

The method of infrared spectroscopy made it possible to track the dynamics of changes in all important types of bonds in molecules of erythrocyte membranes at the stages of their storage at positive temperature. The results clearly showed that the presented method of application of nanotechnology significantly increases the storage time of RBCs in different versions of preservatives due to mechanisms to reduce violations of the molecular structure of proteins and lipids in the erythrocyte membranes. In the future, with used nanotechnologies is planned to continue to study the features of metabolic processes of preserved RBCs at storage stages at positive temperature. Nevertheless, today it is obvious that the presented method of application of nanotechnology is not only safe for use in practice in the Blood Service, Transfusiology and Hematology, but also is the most promising innovation project.

\section{References}

1. Hess JR (2006) An update on solutions for red cell storage. Vox Sang 91(1): 13-19.

2. Högman CF, Meryman HT (1999) Storage parameters affecting red blood cell survival and function after transfusion. Transfus Med Rev 13(4): 275-296.

3. Hess JR (2010) Red cell changes during storage. Transfus Apher Sci 43(1): 51-59.

4. Zimrin AB, Hess JR (2009) Current issues relating to the transfusion of stored red blood cells. Vox Sang 96(2): 93-103.

5. Van de Watering L (2011) Red cell storage and prognosis. Vox Sang 100(1): 36-45.

6. Wang D, Sun J, Solomon SB, Klein HG, Natanson C (2012) Transfusion of older stored blood and risk of death: a meta-analysis. Transfusion 52(6): 11841195.

7. Glynn SA (2010) The red blood cell storage lesion: a method to the madness. Transfusion 50: 1164-1169.

8. D'Amici GM, Rinalducci S, Zolla L (2007) Proteomic analysis of RBC membrane protein degradation during blood storage. J Proteome Res 6(8): 32423255 .

9. Verhoeven AJ, Hilarius PM, Dekkers DW, Lagerberg JW, de Korte D (2006) Prolonged storage of red blood cells affects aminophospholipid translocase activity. Vox Sang 91(3): 244-251.

10. Sparrow RL, Veale MF, Healey G, Payne KA (2007) Red blood cell (RBC) age at collection and storage influence RBC membrane-associated carbohydrates and lectin binding. Transfusion 47(6): 966-968. 


\section{Medical Journal of Clinical Trials \& Case Studies}

11. Bosman GJ, Lasonder E, Groenen-Döpp YA, Willekens FL, Werre JM, et al. (2010) Comparative proteomics of erythrocyte aging in vivo and in vitro. J Proteomics 73(3): 396-402.

12. Belousov AN (2011) The use of magnetite nanoparticles in applied medicine. International Journal of Nano Dimension 2(1): 25-28.

13. Belousov AN, Belousova E Yu (2002) The first steps in discovery new mechanisms of cellular regulation in means by nanotechnology preparations // X International Conference New Information Technologies in Medicine and Ecology, Yalta, Gursuf, pp: 420-425.

14. Belousov AN, Belousova E Yu (2012) Mechanisms cell regulation by nanotechnology preparations (MCS-B). Bio Nanotech Conference \& Expo pp: 18-21.

15. Belousov AN (2000) Effect of magnet controlled sorbent on parameters of acid-base balance of the blood and the processes of glycolysis in erythrocytes. Pain, anesthesia and intensive care. Kiev 1: 263-265.

16. Belousov AN, Nevzorov VP (1997) Ultrastructure of cells in the kidneys and lungs of rabbits after administration of magnetite. International collection of scientific papers IV Scientific and Practical Conference on the Creation and Testing of New Drugs. Moscow 4: 77-87.

17. Belousov AN, Nevzorov VP (1997) Ultrastructure of liver cells after administration of magnetite. International collection of scientific papers IV Scientific and Practical Conference on the Creation and Testing of New Drugs. Moscow 4: 71-77.

18. Belousov AN (2009) Spectrum of Application Magnetite Nanopaticles in Medicine. Nanotech, Chapter 3, ISBN: 978-1-4398-1783-4, 2: 154-157.

19. Belousov AN (2012) Effect on hemolysis and transport ATPase activity of erythrocytes by means nanopareticles of magnetit controlled sorbent (MCSB). Pain, anesthesia and intensive care. Kiev 1: 26-28.

20. Belousov AN (2017) Ultrastructure of Hepatic Cells after Intravenous Injection of Magnetite Nanoparticles ICNB. J Cell Mol Biol 2(1): 1-4.

21. Belousov AN (2013) Application Magnetite of Nanoparticles (ICNB Preparation) as MagneticallyResonant Contrasting Means During Visualization of
Tumours. Clean Technology and Sustainable Industries Organization, Chapter 10, pp: 379-381

22. Belousov AN (2012) Investigation of the influence nanoparticles of magnetite controlled sorbent (MCSB) on the functional activity of erythrocytes. Prospects Medicine and Biology. LSMU. V. IY, 1: 9497.

23. Belousov AN (2014) Myth and Reality Application of Magnetite Nanoparticles as Selective Contrasting Means of the Malignant Tumors in MRI Investigation. Journal Biomedical Engineering Research Sept 2(3): 147-152.

24. Belousov AN (2014) Application of Biocompatible Standardized Magnetite Nanoparticles (ICNB) In MRI Investigation of Malignant Tumour. Journal Nanomaterials \& Molecular Nanotechnology, pp: 1721

25. Belousov AN (2013) Application Magnetite of Nanoparticles (ICNB Preparation) as MagneticallyResonant Contrasting Means During Visualization of Tumours. Journal Clean Technology and Sustainable Industries Organization, Chapter 10, pp: 379-381.

26. Belousov AN (2014) Nanotechnology and Discovery of a New Factor Which Influences on Permeability of Erythrocytes and Eryptosis. Journal of Materials Science and Engineering A 4(11): 367-372.

27. Belousov A, Malygon E, Yavorskiy V, Belousova E (2018) Application of the Standardized Form Magnetite Nanoparticles (ICNB) in Creature Simple and Practical Method of Additive Modernization of Preservation Solutions for Red Blood Cells. Advances in Bioengineering \& Biomedical Science Research. Opast Group LLC. USA, 1(3): 1-7.

28. Belousov A, Malygon E, Yavorskiy V, Belousova E (2018) The Creature of the New Effective Methods Modernization Preservative Solution for Red Blood Cells by Means Preparations of Nanotechnology. International Journal of Nanotechnology \& Nanomedicine 3(2): 1-8.

29. Belousov A, Malygon E, Yavorskiy V, Belousova E (2018) Simple and practical method of Additive Modernization of Preservation Solutions that does not violate the Compliance requirements and Improved the Quality, Efficiency, Safety Transfusion 
of Preserved RBCs. International Journal of Hematology and Blood Disorders 3(2): 1-9.

30. Vijaya Ushasree U, Adee Ahmad (2017) FTIR Spectroscopic analysis on human blood groups. International Journal of Science Environment and Technology 6( 3): 1685-1689.

31. Verbalovic VP (1977) Infrared spectroscopy of biological membranes. Science. The Kazakh SSR, Alma-Ata, pp: 127.

32. Kozitsina LA, Kupletskaya NB (1971) Application of UF, IR and IMR spectroscopy in organic chemistry M, pp: 213.

33. Cross A (1961) Introduction to practical infrared spectroscopy. Publishing House for Foreign Literature, Moscow, pp: 110.

34. Babushkin AA, Bazhulin PA, Korolev FA (1962) Methods of spectral analysis. Publishing house of the Moscow University, pp: 509.
35. Gribov LA (1965) Introduction to the theory and calculation of vibrational spectra of many molecules. Ed. LGI, pp: 134.

36. Kesler I (1964) Methods of infrared spectroscopy in chemical analysis. M The World pp: 257.

37. Mihai Gutu, Mihaela Avadanei, Mihai Marinca, Cipriana Stefanescu (2017) Exploratory Infrared Spectroscopy study of erythrocytes in cancer chemotherapy. Rev Roum Chim 62(2): 181-190.

38. Myshkin VF (2012) Structure and properties of water irradiated by microwave radiation. The scientific journal of the Kuban state agrarian University, 81(07): 1-12.

39. Voevoda MI, Kruchinina MV, Peltek SE (2012) The use of optical methods of blood tests in the diagnosis of the disease stage in diffuse liver disease. Archive of internal medicine 4(6): 46-54. 